\title{
La llegada del Pasmo de Rafael a Madrid y su instalación en el altar de la capilla del Alcázar por Herrera Barnuevo
}

\author{
The arrival of the Pasmo of Raphael to Madrid \\ and its instalation in the altar of the chapel in the \\ Alcázar by Herrera Barnuevo
}

Juan CRUZ YÁBAR

Museo Arqueológico Nacional

Resumen: Aclaramos las circunstancias de la venida del Pasmo de Rafael a Madrid en 1661, durante el reinado de Felipe IV: el interés por esta pintura desde Felipe II, la resistencia de los sicilianos a su salida, la compensación al convento y abad propietarios y el título que se dio al cuadro. También nos ocupamos de la instalación de la pintura en el altar de la capilla del Alcázar, e identificamos un dibujo arquitectónico de Sebastián de Herrera Barnuevo como primera idea del marco y adorno en el que se presentó el Pasmo a la Corte, que sirvió como retablo definitivo.

Palabras clave: Pasmo, Sicilia, Rafael, Madrid, Alcázar, Retablo, Felipe IV, Herrera Barnuevo.

ABstract: We clarify the circumstances of the arrival of Raphael's Lo Spasimo at Madrid in 1661, during Philip IV's reign: the interest in this painting since Philip II, the Sicilians' reluctance to the painting was out, the compensation to the owners (convent and abbot) and the title that was given it. Also we look after the installation of the painting on the altar of the Palace chapel and identify Sebastian Herrera Barnuevo's architectural drawing as a first idea of the frame and adornments in which Lo Spasimo was presented to the Court, that was good as a definitive altarpiece.

Keys words: Pasmo, Sicily, Raphael, Madrid, Alcázar, Altarpiece, Philip IV, Herrera Barnuevo.

\section{EL PASMO, DE SICILIA A MADRID}

El Museo Nacional del Prado conserva entre sus fondos una pintura celebérrima de Rafael conocida como el "Pasmo de Sicilia" (P-298) (Fig. 1). Firmada, se suele datar hacia 1515-1516, porque en 1517 grabó Agostino
Veneziano la composición acabada. Mide 318 x $229 \mathrm{~cm}$ y originalmente fue un óleo sobre tabla, aunque en el siglo XIX se trasladó a lienzo $^{1}$. Representa la Caída en el camino del Cal-

\footnotetext{
${ }^{1}$ Lo sacaron los franceses de España en 1813 y en París fue restaurado y pasado a lienzo. Devuelto en 1818, pasó al siguiente año a nutrir los fondos del nuevo Museo
} 
vario, y fue encargado por el doctor en leyes siciliano Giacomo Basilicò y su mujer Eulalia $\mathrm{de}^{\prime}$ Rosolimini, para su capilla en la iglesia conventual de Santa Maria dello Spasimo en Palermo, perteneciente a la orden olivetana ${ }^{2}$.

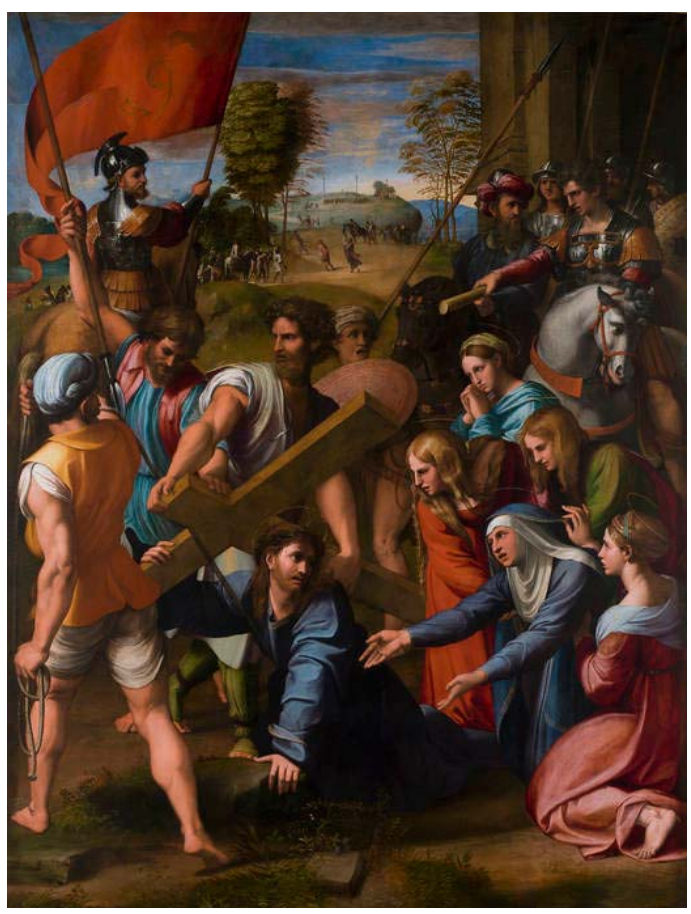

- Fig. 1. Rafael, El Pasmo de Sicilia, h. 1515-1516. Museo Nacional del Prado, P- 298.

de Pinturas. M. de VILLA-URRUTIA, Algunos cuadros del Museo del Prado. Como se recobraron y salvaron de segura ruina los de Rafael que se llevó Bonaparte, París-Buenos Aires, 1900, pp. 64-65, y P. de MADRAZO, Viaje artístico de tres siglos por las colecciones de cuadros de los reyes de España, desde Isabel la Católica hasta la formación del Real Museo del Prado, Barcelona, 1884. Citados por A. MORENO GARRIDO, "Un dato inédito para la historia del «Pasmo de Sicilia» de Rafael", Boletín del Museo del Prado, II, 1981, pp. 159-162.

${ }^{2}$ M. A. SPADARO, “Rivedremo l'altare di Antonello Gagini allo Spasimo?", en G. CASSATA, E. DE CASTRO, y M. M. DE LUCA (eds.), Il quartiere della Kalsa a Palermo: dalle architetture civili e religiose delle origini alle attuali articolate realtà museali: atti del ciclo di conferenze e attività di aggiornamento per docenti, Palermo, 2013, pp. 79-90. En la restante literatura se dice que fue encargado para el altar mayor con un asunto acorde a la advocación conventual (Santa Maria de las Angustias), pero el presbiterio es demasiado grande para tener solamente este cuadro y su retablo. Pasó en 1573 a la nueva sede de los olivetanos, el convento del Santo Spirito, ahora sí en la capilla mayor, por ser de menores dimensiones y porque los monjes tendrían derecho a colocarlo ahí.
La crítica ha señalado algunas debilidades compositivas y cromáticas, que ha disculpado por la intervención de varias manos del obrador de Rafael $^{3}$, por ser su primer cuadro grande de altar ${ }^{4}$-aunque había abordado otros géneros con composiciones mucho más ambiciosas- $y$ porque en su última etapa evolucionó del clasicismo sereno a atrevimientos que anunciaban el Manierismo, de modo que esas incorrecciones pudieron ser en parte conscientes. También influiría que la obra no fuera para Roma, y así, un tapiz que sigue el grabado de Veneziano, tejido seguramente por Pieter van Aelst (1509-1555) y su obrador en Bruselas, encargado por un amigo del pintor, el cardenal romano Bernardo Dovizi da Bibbiena $^{5}$, muestra una mayor coherencia ${ }^{6}$. Aún así es del maestro la idea general, como demuestran dos dibujos preparatorios para figuras de la Albertina y los Uffizi, y constituye una insigne obra maestra para la época; Vasari en sus Vite apuntó que era más famoso en Sicilia que el Etna ${ }^{7}$.

El tratadista aretino añadió que al enviarse la obra hacia la isla naufragó el barco, y solo se salvó la pieza embalada que, milagrosamente, recaló intacta en las costas de Génova. Fue necesaria la intervención del papa León X para que los genoveses restituyeran el cuadro a sus propietarios ${ }^{8}$. Ya desde

${ }^{3}$ En esos años estaba muy solicitado en la basílica de San Pedro, no solo como pintor (Stanze), sino como su arquitecto, y en proporcionar los modelos para tapices de la capilla Sixtina, sin contar otras actividades adicionales pictóricas, anticuarias y urbanísticas en Roma.

${ }^{4}$ Anteriormente solo había llevado a cabo el menor Entierro de Cristo (1507, Roma, Galleria Borghese).

${ }^{5}$ Presenta sus armas y lo mencionó en su testamento de 1520 (J. SHEARMAN, Raphael in Early Modern Sources, 1483-1602, New Haven y Londres, 2003, pp. 629-630).

${ }^{6}$ Para un comentario extenso y una puesta al día de la historiografía del mismo, vid. T. HENRY, y P. JOANNIDES, “El Pasmo de Sicilia” en El último Rafael, Catálogo de la exposición, Madrid, 2012, pp. 94-102.

${ }^{7}$ G. VASARI, Le vite de' piu eccellenti pittori, scultori, $e$ architettori..., Florencia, 1568, t. II, p. 79.

${ }^{8}$ Ibídem: "Qesta tavola finita del tutto, ma non condotta al suo luogo, fu vicinissima a capitar male, percio- 
antiguo se advirtió que esta historia debía ser apócrifa y buscaba dar mayor realce a la obra $^{9}$. En todo caso estaba antes de 1519 en su emplazamiento panormitano, porque el escultor Antonello Gagini (1478-1536) contrató entonces un marco o retablo para la capilla de San Jorge de la nación genovesa en la iglesia del conventual de San Francisco, que debía seguir la forma y calidad del que tenía el Pasmo ${ }^{10}$. En 1573 se trasladaron los olivetanos a la iglesia del Santo Spirito del Vespro, extramuros de Palermo, llevándose consigo la tabla con su retablo ${ }^{11}$.

La estimación por el cuadro atrajo la atención de los Austrias españoles. Gérard ${ }^{12}$

che, secondo che $\mathrm{e}^{\prime}$ dicono, essendo ella messa in mare, per essera portata in Palermo, una orribile tempesta, percosse ad uno scoglio la nave, che la portava di maniera, che tutta si aperse, e si perderono gli huomini, e le mercanzie, eccetto questa tavola solamente, che così incassata come era fu portata dal mare in quell di Genova; dove ripescata, e tirata in terra, fu veduta essere cosa divina, e per questo messa in custodia; essendosi mantenuta illesa, e senza macchia, o difetto alcuno, percioche sino alla furia de' venti, e l'onde del mare hebbono rispetto alla bellezza di tal opera, della quali divulgandosi poi la fama, procacciarono i Monaci di rihaverla, e appena, che con favori del Papa ella fu renduta loro, che satisfecero, e bene, coloro che l'havevano salvata. Rimbarcatala dunque di nuovo, e condottola pure in Sicilia, la posero in Palermo, nel qual luogo ha più fama, e riputatione, che'l monte di Vulcano".

${ }^{9}$ Recientemente Ferino ha advertido un cierto paralelo entre esta historia y la de otra Virgen siciliana, la de Trapani, que se trasladó desde Palestina y quedó en Sicilia por una tempestad que obligó al barco que la llevaba a atracar (S. FERINO PAGDEN, "From Cult Images to the Cult of Images: the Case of Raphael's Altarpieces", en P. HUMFREY y M. KEMP (eds.), The Altarpiece in the Renaissance, Cambridge, 1990, pp. 165-189, espec. pp. 172-174; citado por L. PON, "A Note on Lázaro Díaz del Valle and Raphael's Spasimo di Sicilia in Spain", Boletín del Museo del Prado, XXIX, 2011, pp. 97-103). Vasari ponía así la imagen rafaelesca a la altura de la medieval.

${ }^{10} \mathrm{El}$ encargo de los genoveses pudo tener algo que ver en la historia del naufragio de Vasari.

${ }^{11}$ El retablo fue trasladado sucesivamente de sedes, siendo identificados sus restos desmontados por Spadaro en 1986; actualmente se prepara su montaje (vid. M. A. SPADARO, Op. cit.).

${ }^{12}$ V. GÉRARD, “Los sitios de devoción en el Alcázar de Madrid: capilla y oratorios", Archivo Español de pensó que Felipe IV lo quiso para el altar mayor de la capilla real del Alcázar madrileño con motivo de su reforma de 1639 para el nuevo relicario ${ }^{13}$. Sin embargo, el interés venía ya desde Felipe $\mathrm{II}^{14}$, quien no consiguió

Arte, 223, 1983, pp. 275-283. Es de la misma opinión A. ATERIDO FERNÁNDEZ, “Conjuntos iconográficos en el Alcázar de Madrid en época de Felipe IV: nuevas visiones", en J. M. PITA ANDRADE (dir.) y A. RODRÍGUEZ REBOLLO (coord.), Tras el centenario de Felipe IV. Jornadas de Iconografía y Coleccionismo dedicadas al profesor Alfonso E. Pérez Sánchez del 5 al 7 de abril de 2006, Madrid, 2006, pp. 305-326.

${ }^{13}$ Lució en el altar hasta ponerse el Pasmo en 1663 la copia del políptico de San Bavón de Gante de los hermanos van Eyck hecha por Michel Coxcie, que se dio entonces al convento de Santa Isabel según M. FRASO, Tratado de la Capilla Real de los Serenísimos Reyes Católicos de España..., Madrid, 1685, cap 1, fols. 2 v.-8 v. Se pensaría para el altar mayor agustino, pero en 1664 se encargó a Sebastián de Benavente un retablo para el lienzo de la Concepción de Ribera (J. M. CRUZ YÁBAR, Sebastián de Benavente (1619-1689) y el retablo cortesano de su época, Tesis doctoral defendida en la Universidad Complutense, Madrid, 2013, t. II, pp. 363-370)

${ }^{14}$ D. GARCÍA CUETO, Seicento boloñés y siglo de oro español: el arte, la época, los protagonistas, Madrid, 2006, p. 148, afirma esto mismo sin aportar pruebas. Éstas se encuentran en un memorial del convento del Santo Spirito y su abad presentado a Felipe IV por septiembre de 1661, en que se decía de la pintura: “y de que el señor Rey don Phelipe Segundo y otros señores Reyes antecessores de Vuestra Magestad han ofrecido diversas sumas de ducados, por medio de sus Virreyes, para conseguirle", lo que se confirma en la respuesta real "y haviendo tantos Virreyes de Sicilia hecho diligencia para remitirla a España y ofrecido por ella tan suvidos precios, sin haverlo podido conseguir ninguno" (documentado en J. A. CEÁN BERMÚDEZ y M. R. ZARCO DEL VALLE, "Noticias exactas y curiosas del cuadro original de Rafael de Urbino, llamado El Pasmo de Sicilia, que existe ahora en el Real Museo de Madrid", El Arte en España, VI, 1867, pp. 202-208. Fueron incluidos también en M. R. ZARCO DEL VALLE, Documentos inéditos para la historia de las bellas artes en España, Madrid, 1870, pp. 144-155). El pintor y teórico valenciano Vicente Vitoria, en su manuscrito romano Academia de la Pintura del Señor Carlos Maratti, citado por M. MENA MARQUÉS, "Presencia histórica de obras de Rafael en España", en Rafael en España, Catálogo de la exposición, Madrid, 1985, pp. 1128 , especialmente pp. 16-17, y fechada por esta autora hacia 1690, escribió: "Muchos años hacía que los Reyes de España desseavan esta pintura; pero era su deseo vano porque en dos ocasiones que hicieron el tentativo de sacarlo estuvo para rebelarse Palermo". 
sino una copia de pequeño tamaño ${ }^{15}$. Había además otras versiones en la corte ${ }^{16}$, donde la legendaria historia de Vasari la había propagado en el imaginario colectivo ${ }^{17}$. Estos precedentes hacen innecesario recurrir a fuentes que tuviera Felipe IV, como un ejemplar de las Vite y un grabado del Pasmo de 1565, para elegir la obra "por catálogo"18. Es sobradamente conocida su predilección por Rafael, pues en estos años adquirió varias obras suyas $^{19}$. El Pasmo era una de las grandes composiciones del urbinés adecuadas

${ }^{15}$ La envió don Juan de Cardona en 1578; documentado por D. GARCÍA CUETO, Op. cit., p. 148. Ha de ser la que figura en el Palacio del Buen Retiro según los inventarios reales de 1772 y 1789 ("585. Otra tabla maltratada de Cristo con la Cruz a cuestas copia del Pasmo de Sicilia vara y quarta de alto mas de tres quartas de ancho") y 1789 (1061. Otra en tabla del Pasmo de Sicilia copiado por alguno de los discípulos de Rafael de Urbino: representa a Cristo con la Cruz a cuestas en la Calle de la Amargura: de vara y media quarta de alto y tres quartas de ancho"). En 1814 estaba en el Palacio Real y hoy pertenece, muy deteriorada, al Museo del Prado (P-7195; mide 95 x 69 cm). Vid. para los datos J. M. RUIZ MANERO, "Pintura italiana del siglo XVI en España. II: Rafael y su escuela", Cuadernos de Arte e Iconografía, 10, 1992, pp. 7-234, especialmente 67-68.

${ }^{16}$ Entre las enumeradas en J. M. RUIZ MANERO, Op. cit., es con seguridad anterior a la llegada del Pasmo en 1661 la del Almirante de Castilla mencionada en el inventario de sus bienes de 1647.

${ }^{17}$ Así lo reconocía el monarca en la contestación a la consulta citada "Esta pintura es tan conocida y celebrada como se sabe" (vid nota 15).

${ }^{18}$ A. ATERIDO FERNÁNDEZ, Op. cit., p. 316. Idea seguida por L. PON, Op. cit., p. 98.

${ }^{19}$ Eran de menor tamaño y con asuntos menos adecuados para el altar mayor de la capilla real; fueron enviadas todas al Escorial. La Virgen del Pez procedente de San Domenico de Nápoles, vendida por el general dominico -pese a la oposición del prior- al duque de Medina de las Torres, quien la regaló a Felipe IV, se colocó en la iglesia vieja tras llegar en 1645. En 1649 compró el embajador en Inglaterra don Alonso de Cárdenas la Sagrada Familia en la almoneda de los bienes de Carlos I y la debió adquirir don Luis Méndez de Haro, quien en 1654 la dio a Felipe IV; en el altar de la sacristía la citó el capellán real Jules Chifflet en 1656 (Documentos para la historia del Monasterio de San Lorenzo el real de El Escorial, t. VII, Madrid, 1964, p. 407). La Visitación de San Silvestre en L' Aquila, llegada en 1655 a España, fue destinada a la sacristía. para un retablo de cierto tamaño y la única en sus dominios italianos que podría llegar a obtener ${ }^{20}$.

Distintas fuentes dejan traslucir que don Fernando Fonseca, conde de Ayala, virrey de Sicilia entre 1660 y 1664, dirigió unas negociaciones con los olivetanos en nombre de su señor, sin que la opinión pública conociera que éste era el interesado último y que Ayala cumplía un papel de intermediario ${ }^{21}$. Como propuso García Cueto, tuvo que influir en la orden el cardenal Facchinetti, pues era su protector y tenía buena relación con el Rey y su valido, don Luis Méndez de Haro ${ }^{22}$. Hubo terremotos en Palermo en febrero de 1661 relacionados por un cronista de fines del siglo con la salida del cuadro, aunque ésta fue posterior, por lo que tendrían lugar durante los $\operatorname{contactos}^{23}$.

${ }^{20}$ La otra posibilidad hubiera sido la Transfiguración, aunque no su original de 1516, conservado en Roma, sino la copia $(396$ × $263 \mathrm{~cm})$ de Giulio Romano y Gianfrancesco Penni posterior a 1520, que pasó poco después a Nápoles al hospital del Santo Spirito degli Incurabili, donde la compró el virrey duque de Medina de las Torres en 1638. Fue donada en 1684 por el hijo del duque, el príncipe de Stigliano, a su fundación madrileña de las carmelitas descalzas de Santa Teresa, donde se colocó en el retablo mayor (G. CRUZADA-VILLAAMIL, Catálogo provisional...del Museo Nacional de Pinturas, Madrid, 1865, pp. 257-258). Se conserva en el Museo del Prado (P-315).

21 "Quà è venuto avviso che in Palermo por causa d'una pintura che voleva quel Viceré seguisse tumulto e qua parim.e la Citta Missina ha fatto dar memorial a S. M. d'aggravy e d'inosservâza delle loro leggi da Sud. Sr. ViceRe"; documento fechado en Roma el 11 de mayo de 1661 (M. J. MUÑOZ GONZÁLEZ, “La Capilla Real del Alcázar y un altar de pórfido", Reales Sitios 164, 2005, pp. 50-69, especialmente pp. 50 y 67). En otra versión encontramos: "questo pretiosissimo Quadro fù datto da i Padri Olivetani di quel Monasterio al Vicerè Conte d'Ayala, il quale ne fece un bel dono à Sua Maestà, onde fu posto nella sua Real Capella" (V. AURIA, Historia cronologica delli signore vicerè di Sicilia: dal tempo che mancò la personale assistenza de' Serenissimi Rè di quella: cioe dall anno 1409 sino al 1697 presente, Palermo, 1697, citado por A. ATERIDO FERNÁNDEZ, Op. cit., p. 325).

$$
{ }^{22} \text { D. GARCÍA CUETO, Op. cit., p. } 146 .
$$

23 "Ma fu cosa notabile, che mente si preparava la Traslatione di quel Ritratto di Palermo à Madrid si come nell'acerba Passione del nostro Redentore, occorse quell 
La inminente marcha del cuadro provocó un fuerte rechazo de los sicilianos ${ }^{24}$, según conocemos por el documento romano de mayo de $1661^{25}$ y por la carta de don Cristóbal de Torres y Medrano a su señor el marqués de Villena, redactada en Madrid el 17 de septiembre de aquel año: "tan celebrada de los sicilianos, por lo primoroso del arte, y por la circunstancia de estar colocada en un convento donde sucedió aquella memorable venganza de las vísperas sicilianas, embiola el Conde de Ayala a pesar de toda la ciudad, cuyo sentimiento casi prorrumpió en tumulto, $\mathrm{y}$ se temieran mayores novedades si la paz no estubiera de por medio" ${ }^{26}$. Todavía en 1669 recordaba el futuro gran duque de Toscana Cosme III de Medicis al visitar la Capilla Real madrileña y ver la tabla "cuyo transporte de Sicilia a España fue ocasión de extraños movimientos en aquel reino"27. El abad del convento que la trajo a Madrid, Clemente Staropoli, temía represalias de no obtener merced real $^{28}$, y Vicente Vitoria anotó que el rey dio

portentoso Terremoto per tutto il Mondo, così pure s'udirono in Palermo, ed in alcune città di Sicilia, spaventevoli scotimenti della Terra, che mossero I popoli a gran dolore delle lor colpe, e particularmente in Palermo più volte à 13 e 24 di Febbraio 1661", V. AURIA, Op. cit., p. 130, citado por E.-B. KREMS, Raffaels römische Altarbilder: Kontext, Ikonographie, Erzählkonzept: Die Madonna del Pesce und Lo Spasimo di Sicilia, Munich, 2002, pp. 171267, especialmente p. 176.

${ }^{24}$ A pesar del tono adulatorio de Facchinetti en una carta del 23 de mayo de 1661 al rey "huélgase toda Italia de que a las reales manos de Vuestra Magestad lleghe tan admirable portento di un pincel que fue milagroso, y lo será todo el tiempo que durare el mundo" (J. A. CEÁN BERMÚDEZ y M. R. ZARCO, Op. cit.).

${ }^{25}$ Vid. nota 21.

${ }^{26}$ A. MORENO GARRIDO, Op. cit. La carta formaba parte en 1981 de una colección particular donde se conserva un corpus de correspondencia entre don Cristóbal de Torres y Medrano y el marqués de Villena. L. PON, Op. cit., p. 102, indica que el autor de la carta aparece como regente de las escribanías mayores de los privilegios y confirmaciones y da a conocer otros datos sobre su vida y publicaciones.

${ }^{27}$ A. MORENO GARRIDO, Op. cit., p. 162.

${ }^{28}$ Vid. nota 39 (memorial de 1662): "y bolver a los ojos de la emulación que le a grangeado en aquel Reyno una pensión al abad "que con tanta sagacidad consiguió la tan peligrosa transportación de aquella aunque súbdita ciudad" 29 .

Accedieron los olivetanos por no contradecir la voluntad real. García Cueto ${ }^{30}$ intuyó que esperarían una generosa compensación, pero se trató de una elevada contraprestación disfrazada de real magnanimidad. En misiva del conde de Ayala a don Luis de Haro desde Palermo el 30 de junio de 1661 recomendaba compensar al convento y a su abad "por haber accedido a entregar el célebre cuadro de Rafael, llamado Lo Spasimo, cuando se les pidió en nombre de S. M." ${ }^{31}$. El propio Staropoli viajó a Madrid con el cuadro y cartas de recomendación fechadas en Roma el 23 de mayo por el cardenal Facchinetti y el abad general de los olivetanos, Angelo Maria Torelli ${ }^{32}$. Sin duda quería asegurarse de que el cuadro llegara bien y vigilar que los españoles cumplieran su parte. En el puerto de Cartagena le esperaba Francisco Rizi, según se conoce por sendos memoriales suyos de 1669 y $1673^{33}$. Por la carta de Torres y Medra-

este servicio sin el premio esperado de Vuestra Magestad sería quedar destruydo y hecho blanco de torcidas intenciones contra su estimación, y lo que mas es, la que puede y debe darle el haver llegado a sus reales plantas; que crece el encono de lo que refiere a Vuestra Magestad en términos, que se halla con aviso de que su religión quiere poner otro Abbad en su lugar; cuyas oposiciones no tienen mas remedio que el effecto de la fe puesta en la merced que de Vuestra Magestad espera, y ella será bastantísima a lucirle contra todos" (J. A. CEÁN BERMÚDEZ y M. R. ZARCO, Op. cit.).

${ }^{29}$ Vid. nota 14.

${ }^{30}$ D. GARCÍA CUETO, Op. cit., p. 146.

${ }^{31}$ D. de BERWICK Y ALBA, Discusos leídos ante la Real Academia de Bellas Artes de San Fernando en la recepción pública del excmo. Sr. Duque de Berwick y de Alba, Madrid, 1924, p. 92.

32 Staropoli las entregó en octubre, según rezan las síntesis entregadas al rey (J. A. CEÁN BERMÚDEZ y M. R. ZARCO, Op. cit.).

33 "Trujo la pintura de Rafael que oy está en la Capilla Real” (J. SIMÓN, “Francisco Rizi, postergado", Archivo Español de Arte, XVII, 1945, pp. 308-309). Aterido ha reparado en que Staropoli ofició la boda de Rizi con Juana de Ayala el 13 de noviembre de 1661 (A. ATERIDO FERNÁNDEZ, Op. cit., p. 318, según documentación de 
no sabemos que, al menos desde el 15 de septiembre, estaba ya la tabla en Madrid: "Antes de ayer vi en la quadra ochavada de palacio, aquella pintura de Palermo" ${ }^{\prime 34}$.

La cuestión de los beneficios solicitados y de los concedidos a los poseedores del Pasmo no ha sido interpretada correctamente. El convento, por medio de su abad -seguramente en la segunda mitad de septiembre de 1661- presentó un memorial al monarca con sus pretensiones: la abadía della Maggione de Palermo tenía 10.000 escudos anuales de renta, de los que 3.000 se destinaban a la celebración de los oficios divinos por capellanes y otras personas designados por su abad y para otros efectos. Los olivetanos querían que se les concediera en exclusiva el ocuparse de este culto divino con su derivada renta y, además, alguna pensión a cargo de los 7.000 escudos sobrantes que administraba el abad; si no fuera posible, se conformarían con otra renta sobre algo fijo para poder edificar un nuevo convento dentro de la ciudad ${ }^{35}$.

M. AGULLÓ Y COBO, "Antonio y Francisco Rizi", Anales del Instituto de Estudios Madrileños, XXXVI, 1996, pp. 75-97, especialmente pp. 81 y 86-87). Imaginamos que el abad presenciaría el bautizo del futuro Carlos II ocho días mas tarde. El papel de Rizi fue importante, y de ahí que lo citara en sus memoriales para mejorar su situación como criado del rey. Sin duda ejercería a modo de moderno correo, inspeccionando que el cuadro no hubiera sufrido daños y que el embalaje fuera suficiente para evitarlos en el trayecto a Madrid. Para conocer mas detalles en torno a esta cuestión, vid. P. F. SALVO, "Il trasporto del quadro dello Spasimo a Madrid", en Atti del seminario di studio sul complesso monastico-militare dello Spasimo a Palermo, Palermo, 1987, pp. 147-149.

${ }^{34}$ Vid. nota 26.

35 “Propone por medio que la Abbadía de Maxione tiene de valor diez mil escudos, y sobre sí cargas que importarán hasta tres mil, que se reparten cada año entre los capellanes que celebran los oficios divinos y otras personas y cosas necesarias para este Ministerio, las quales nombra el Abad propietario de dicha Abbadía. Y el convento dize que pues estas cargas que tiene por precissas dichas Abbadía se dirigen al culto divino, y no hay inconveniente que pueda obstar a que los monges del Monasterio de Santa María puedan oficiar aquellas ocupaciones, sin que le siga por esto perjuicio alguno al Abad propietario de la Maxione, suplican a Vuestra Magestad les haga merced de dar al Monaste-
El Consejo de Italia propuso al rey que rechazara esta insinuación relativa a la Maggione, la abadía más importante de Sicilia, pues disminuiría sus privilegios y los de sus abades. Ofreció como alternativa una renta anual de 1.000 ducados, 500 situados sobre los efectos de expolios y sedes vacantes, y otros tantos sobre las tratas de granos; si faltasen algún año se suplirían con los efectos ordinarios y extraordinarios de la hacienda del reino de Sicilia. Así podrían reparar su convento o invertir en su decoración o culto, pero no mudarse del sitio que ocupaban extramuros ${ }^{36}$. Felipe IV atendió a las razones del Consejo, pero había queda-

rio alguna renta de pensión sobre los siete mil escudos que le quedan libres al que fuere Abad, y aplicarles los tres mil que tiene de cargas la misma Abadía, quedando obligado el Monasterio a pagarla, reservando en sí lo que se distribuye entre capellanes y demás personas y cossas tocantes al culto divino, que se podrá servir por los religiosos (quedándoles este útil) con la beneración que otro qualquiera sacerdote. Y que en caso que esto parezca difícil, Vuestra Magestad haga merced al Monasterio de la Renta que fuere servido en cosa que sea fija...haciendo esta supplica para poder labrar una casa dentro de la ciudad de Palermo" (J. A. CEÁN BERMÚDEZ y M. R. ZARCO, Op. cit.).

36 “En primer lugar excluye el Consejo la que se insignua de la pensión sobre la renta de la Abbadía de Maxione y aplicación de la que se reparte entre capellanes y culto divino de dicha Abbadía encargándose de uno y otro el Monasterio. Porque la dicha Abbadía es la más calificada de aquel Reyno, y que antiguamente fue Iglesia Cathedral y Metrópoli de Palermo, conserbando por esto actualmente el que el día de Corpus salga della la processión con asistencia del Virrey y Consejos y otras preeminencias y culto que cessarían o se limitarían mucho, y por consiguiente la de los Abades...Por lo qual pareze al Consejo que Vuestra Magestad podría servirse de hazer merced a dicho Monasterio de Santa María del Spasmo de mil ducados de renta perpetua en cada un año, los quinientos en espolios y sedes vacantes del dicho Reyno, con derogación de todas las órdenes que huviere en contrario. Y los otros quinientos en Tratas de granos, con refación entrambos efectos de lo que por algún accidente no se cobrare algunos años se subrogue y cobre en los siguientes, para que con esta renta puedan acudir el Abad y Religiosos de dicho Monasterio a la fábrica o reparo de su Iglesia, al adorno y culto della, pero sin darles permisión para mudarse de aquel sitio que les dio la elección de sus superiores y que es necesario para conserbar la deboción de aquellos súbditos y la memoria de lo que en tiempos passados se experimentó en el sitio de la misma Iglesia" (Ibídem). 
do tan complacido ${ }^{37}$ que aumentó la renta de 1.000 ducados a 4.000, y además añadió una pensión de 500 ducados para Staropoli, ésta sobre las primeras vacantes de obispados que hubiera en aquel reino, más una ayuda de costa para la vuelta ${ }^{38}$. El 22 de abril en Aranjuez firmó los privilegios definitivos para el convento y el $\mathrm{abad}^{39}$, y es de suponer que tuvieron efecto, al menos en los años sucesivos.

Al llegar el rafael a España, el término Spasimo fue castellanizado, pero no se ha destacado que la traducción literal, que sería Espasmo (Angustia), fue abreviada a Pasmo. De este modo, el título no hacía ya alusión al contenido teológico original del cuadro y quedaba descontextualizado de su emplazamiento siciliano; contrariamente, mezclaba el asombro que producía la representación rafaelesca del pasaje evangélico con la excelencia pictórica. Así lo dio a entender una crónica del bautizo del príncipe Carlos, celebrado 21 de noviembre de 1661: “...en que está figurado Christo Señor nuestro, caído en tierra, llevando la cruz a cuestas; a quien saliendo la Virgen al encuentro (acompaña-

37 “Y aviéndomela ymbiado aora aquel convento con la demostración de gusto que se a visto, parece que conviene se rreconozca en Ytalia, que no solo me ha sido grato, sino también la forma en que lo an hecho" (Ibídem).

${ }^{38}$ Aún en Madrid, pero con la necesidad ya de regresar, mandó el abad un memorial que trasladó el Rey al Consejo de Italia el 7 de enero de 1662 en que se remitía a otro anterior, proponiendo en vez de los 500 ducados de renta que se le diese el priorato vacante de Santa María de Burgitabus. En este otro insistía en el priorato por sus servicios y los de sus antepasados a la Corona, pues no podía esperar a que la secretaría revisara la nómina de vacantes. Aún envió Felipe IV al Consejo el 10 de febrero otro memorial del abad, que no había podido situar aún la renta de los obispados, y entretanto pedía que se le pagara de expolios de iglesias vacantes de Sicilia -como al convento-. Recomendó el Consejo el 25 al monarca que se le pagara la renta sobre las iglesias mientras no se situase sobre iglesia fija (Ibídem).

${ }^{39}$ Ibídem. Vitoria escribió mas tarde "ni lo hubiera podido lograr sino hubiera sido por la industria del prior de aquel convento que en tiempos de Felipe IV obtuvo el intento con pensión de pagar a aquel convento mil escudos cada año y le dio un obispado a aquel superior". da de San Juan y las tres Marías) quedó almirada de ver a su preciosíssimo Hijo: y está tan al vivo, y con tanta perfección que le dio su Artífice nombre de Admiración de la Virgen y Pasmo del Mundo" ${ }^{40}$.

Otra cuestión es si Felipe IV designó o no a esta pintura como la Perla, un nombre que hasta entonces había correspondido a la Sagrada Familia de Rafael del Escorial ${ }^{41}$. Chifflet indicó de ésta en 1656: "esta pintura está allí aislada de las demás, como la mas exquisita, pues es cierto que Su Magestad acostumbra a llamarla su favorita" ${ }^{\prime 2}$. Una relación anónima posterior supone el primer testimonio de su denominación: "el que le sigue, que está encima de una ventana y debajo de otra, es la Perla del Sr. don Felipe IV, es tabla, pintura de Rafael" ${ }^{\prime 3}$. Sin embargo Mena presentó la hipótesis de que la cita no fuera referida a la Sagrada Familia sino al Camino del Calvario ${ }^{44}$, porque Vitoria escribió: "Esta pintura se conserva en la Capilla Real de Madrid y me decía el Cardenal de Maximi que la apreciaba tanto aquella Magestad que entre los tesoros de sus pinturas solía llamar a esta la Margarita", y margarita significaría perla en latín ${ }^{45}$. Ruiz Manero ${ }^{46}$, sin extraer consecuencia alguna, halló que Vitoria volvió sobre la cuestión en otro escrito: “e quella Maestà l'aprezzò tanto che fra i te-

${ }^{40}$ Descripción del magestuoso aparato con que se celebró el Bautismo del Príncipe Don Carlos Joseph...el Lunes 21 de noviembre de 1661, transcrito en E. VARELA HERVIÁS, Gazeta Nueva 1661-1663 (Notas sobre la historia del periodismo español en la segunda mitad del siglo XVII), Madrid, 1960, pp. XCV-CI, especialmente p. XCVI.

${ }^{41}$ J. M. RUIZ MANERO, Op. cit., p. 37 refiere que en el inventario de pinturas del Museo del Prado de 1857 figura por primera vez la frase puesta en boca de Felipe IV "He aquí la perla de mis colecciones".

42 Documentos para la historia..., p. 407.

${ }^{43}$ G. de ANDRÉS, "Relación anónima del siglo XVII sobre los cuadros del Escorial", Archivo Español de Arte, 173,1971 , pp. 49-64, especialmente p. 59, la fecha hacia 1698 y la atribuye al prior fray Alonso de Talavera.

${ }^{44}$ M. MENA MARQUÉS, Op. cit., pp. 14-18.

${ }^{45}$ En realidad proviene del griego, margarites.

${ }^{46}$ J. M. RUIZ MANERO, Op. cit., p. 63. 
sori delle sue Picture, soleva chiamar questa il gioiello"47. García Cueto ha aludido a una posible alusión a Margarita, hija de Felipe $\mathrm{IV}^{48}$. A nuestro entender, el rey denominaba "mi perla" a su primer rafael, y, cuando llegó a sus manos el segundo, no privó a la Sagrada Familia de su apodo ${ }^{49}$, sino que buscó un sinónimo, "mi margarita", para elogiar al Pasmo, el nombre con el que se popularizó.

\section{EL PASMO EN EL ALTAR DE LA CA- PILLA DEL ALCÁZAR}

El ya citado don Cristóbal de Torres y Medrano proporciona en su carta del 17 de septiembre de 1661 la noticia más antigua sobre el destino final de la preciada pintura en el Alcázar madrileño "han de poner el cuadro en el altar de la Capilla de Palacio, es de Rafael de Urbinas, y la mas gallarda pintura, que pueda imaginarse, y mas devota"50. Moreno Garrido, que dio a conocer la noticia en 1981, juzgó que quedaba resuelto el problema de la situación de la pintura, presente en la Pieza Ochavada hasta 1662 ó 1663, en que se colocaría en la citada capilla ${ }^{51}$.

Gérard, en 1983, se refirió a documentos del archivo de Simancas que ponían de manifiesto que el cuadro se había trasladado a la capilla real dos meses después de que Torres y Medrano escribiera su carta. Eran unas libranzas para pagar un marco para el Pasmo que se puso en la capilla la víspera del bautismo

${ }^{47}$ V. VITORIA, Osservazioni sopra il libro della Felsina Pittrice per difessa di Raffaello da Urbino, dei Carracci e della loro scuola publicate e divise in sette lettere da...patrizio valenziano e canonico di Xativa, Bolonia, 1703.

${ }^{48}$ D. GARCÍA CUETO, Op. cit., p. 149.

${ }^{49}$ Lo cual sería lógico por el emplazamiento del Pasmo en el espacio religioso mas importante del reino, el esfuerzo que costó a él y sus antecesores conseguirlo, o su tasación en los precios más altos en los inventarios reales posteriores (vid. J. M. RUIZ MANERO, Op. cit.).

${ }^{50}$ A. MORENO GARRIDO, Op. cit., p. 160.

${ }^{51}$ En el inventario del Alcázar de 1686 se menciona esta fecha como la de colocación de la pintura en la capilla. Y. BOTTINEAU, "L' Alcazar de Madrid et l'inventaire de 1686", Bulletin Hispanique, 58, 1956, pp. 421-459, concretamente pp. 439-440. del futuro rey Carlos II el 21 de noviembre de 1661. Según estos documentos, el escultor José Ratés (documentado entre 1651 y 1684) cobró 5.000 reales por una "riquísima cornisa con festones, frutas, ángeles, rematado por escudo y cornisa (sic) real sostenidos por águilas" ${ }^{25}$. Tales características no aparecen en las libranzas sino que mezclan las noticias del pago a Ratés con la descripción del adorno de la pintura en la crónica de Fraso publicada 25 años después.

Aterido examinó en 2006 las copias de los libramientos de los que había dado noticia Gérard, custodiadas en el archivo del Palacio Real de Madrid, y aclaró las fechas, cantidades y conceptos de los pagos ${ }^{53}$. Ratés hizo en realidad un cuadro y adorno de madera de pino en blanco y de peral dado de negro. Desveló también la intervención de don Juan de Villegas en el dorado de talla y adornos del cuadro por 2.500 reales y adjudicó la traza al maestro mayor de las obras reales José de Villarreal por haber dictado las condiciones para la obra. Halló además un memorial del 26 de agosto de 1687 dirigido a la hacienda real por Teresa Ibarra, hijastra del pintor y arquitecto Juan Fernández de Gandía (h.1600después de 1663) que intentaba aún cobrar lo que se adeudaba, entre otras cosas por "... el último servicio que hizo, después de muchos en que puso a riesgo repetidas vezes su vida, fue el del ornato del quadro de la real capilla"54. Aterido pensó que la arriesgada intervención de Gandía para realizar la traza de Villarreal tendría como objeto el aparatoso remate superior descrito por Fraso, pues era especialista en arquitecturas fingidas.

García López ${ }^{55}$ dio a conocer en 2008 un apunte del cantor y cronista Lázaro Díaz

${ }^{52}$ V. GÉRARD, Op. cit., pp. 280-281.

${ }^{53}$ A. ATERIDO FERNÁNDEZ, Op.cit., p 318. El 8 de octubre de 1661 hubo 2.000 reales para Ratés y 1.000 para Villegas, el 19 esta última cantidad para ambos, el 27 otra vez para Ratés, el 2 de noviembre 490 reales para éste, y los últimos 510 el 11; el dorador obtuvo el resto (500 reales) el 14.

${ }^{54}$ Ibídem, p. 319.

${ }^{55}$ D. GARCÍA LÓPEZ, Lázaro Díaz del Valle y las Vidas de pintores de España, Madrid, 2008, pp. 160-162. 
del Valle que añadía nuevos datos ${ }^{56:}$ "Jueves 14 de dicho mes [noviembre de 1661] se vio la primera vez, en el lugar del Retablo del Altar de la Real cappilla de Su Magestad la Preciosa Pintura en tabla del santo christo arrodillado con la cruz a cuestas hecha por Rafael Sancio de Vrbina, cognominado el divino, es Pintura que està apreciada en 30.000 escudos de oro $^{\prime \prime 5}$. El día del bautizo del príncipe, el 21 de noviembre, el cronista refirió así la decoración: "Prevínose la Capilla Real de Palacio... cuyo altar estava muy luzido, y alajado, campeando las admirables pinturas de su Retablo, que contienen la creación de nuestros primeros Padres en el Parayso. Estava pendiente, al lado del Altar, un hermosísimo lienço traído de la Ciudad de Palermo, a instancia del Rey nuestro señor (que es dibuxo del nuevo Apeles de estos tiempos Rafael Urbino)" ${ }^{\prime 58}$.

Después de las citadas publicaciones, los problemas planteados por la instalación del Pasmo se centran principalmente en el tipo de adorno que rodeó a la pintura en la Real Capilla y, en su caso, los cambios acaecidos y sus fechas.

Aterido pensó que el proyecto para colocar el cuadro en la capilla se gestó entre la confirmación del envío de la pintura -mayo según las cartas de recomendación de Staropoli- y la llegada a Madrid en septiembre, de modo que, cuando llegó al Alcázar, el diseño

${ }^{56}$ L. DÍAZ DEL VALLE, Noticia histórica del principio de la Inquisición y la historia y nobleza del Reino de León y Principado de Asturias, Madrid, s. f., fol. 179v.

${ }^{57}$ L. PON, Op. cit., en una edición del Vasari conservada en la Bridwell Library de la Southern Methodist University de Dallas, junto al comentario del italiano al Pasmo -“Una tavola d'un Christo, che porta la croce, la quale è tenuta cosa maravigliosa. Conoscendosi in quella, la impietà de' Crocifissori, che lo conducono alla morte al Monte Calvaio con grandissima rabbia, dove il Christo appasionatissimo nel tormeto dello avvincinarsi alla morte, cascato in terra per il peso del legno della Croce, e bagnato di sudore e di sangue, si volta verso le Marie, che piangono divotissimamente"- identificó una anotación de Díaz del Valle que había poseído el ejemplar: "Pintura del christo con la cruz a cuestas que el Rey don Felipe 4 Nuestro Señor puso en el Altar de la Real capilla del palacio de Madrid en nobiembre de 1661".

${ }^{58}$ Descripción del Majestuoso aparato..., p. XCVI. del adorno estaba preparado ${ }^{59}$. En su opinión se hizo de manera acelerada pues el objetivo sería que luciera en el bautizo del Príncipe, y como en las últimas libranzas del día 11 de noviembre para Ratés y la del 14 para Villegas indican que la obra "se puso" en la capilla real, se sorprendió de que en la ceremonia no estuviera la pintura colocada en el altar. Opinó que los pagos reflejaban un marco sencillo, frente al complejo retablo descrito por Fraso, que se haría después de 1661, quizá ya para la siguiente ceremonia solemne, en 1663. Mencionó la similitud de algunos aspectos del marco arquitectónico que describe éste y el proyecto arquitectónico cuyo dibujo se halla en la Biblioteca Nacional, atribuido sin discusión a Sebastián de Herrera Barnuevo ${ }^{60}$ (Fig. 2). En el reinado de Carlos II se añadirían algunos elementos que explicarían el acusado barroquismo descrito por Fraso.

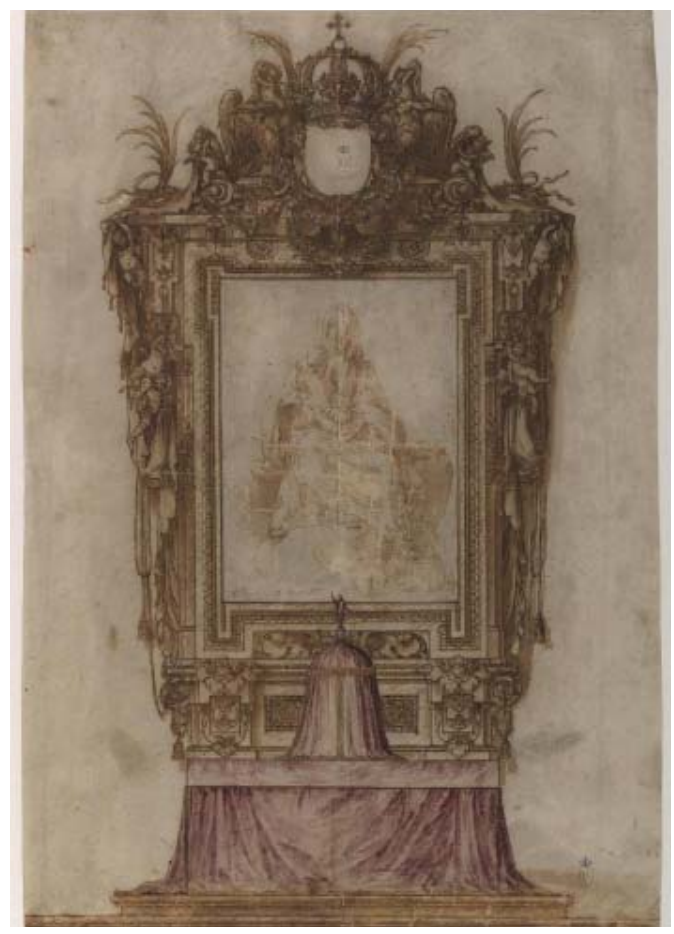

- Fig. 2. Sebastián de Herrera Barnuevo, Proyecto de un ornato, 1661. Biblioteca Nacional de España, DIB 16/35/10.

${ }^{59}$ A. ATERIDO FERNÁNDEZ, Op. cit., p. 318.

${ }^{60}$ Biblioteca Nacional de España, DIB 16/35/10. Es un dibujo a pluma y tinta, con aguadas pardas, carmines, azules y con toques de oro. Mide 433 x $295 \mathrm{~mm}$. 
Nuestra interpretación de los datos expuestos nos lleva a establecer determinadas hipótesis sobre este asunto. Antes destacaremos distintos aspectos que afectan a esta cuestión y que pueden dar lugar a debate.

Se ha de advertir que no tiene soporte documental la propuesta de que existiera un diseño general para colocar el cuadro antes de su llegada a Madrid. Por el contrario, no hay inconveniente en que, cuando llegó, poco antes del 15 de septiembre, se midiera y realizara la traza, que ha de ser anterior a 8 de octubre en que se datan las obligaciones y las primeras libranzas para Ratés y Villegas. Las tres semanas que transcurren entre una $\mathrm{y}$ otra fecha parecen suficientes para que se diseñara el adorno.

Aunque Aterido supuso que se trataba de un marco sencillo porque Ratés y Villegas dispusieron tan solo de un mes para su realización, conviene anotar que era el tiempo habitual para realizar decoraciones efímeras mucho mayores, como los catafalcos para las honras reales ${ }^{61}$. Los altos precios de $5.000 \mathrm{y}$ 2.500 reales para ensamblaje y dorado -más aún en el caso de Ratés, que no había llegado al apogeo de su fama- confirman que la labor fue abundante y difícil. Son cifras adecuadas para un retablo del tipo que se usaba para adosar a un pilar de una iglesia, y el término "cuadro y adorno" que utilizan las libranzas no excluye que, sin llamarle retablo, produjera su efecto si estaba colocado tras un altar. Los materiales confirman esta hipótesis. El peral teñido de negro para imitar al ébano era empleado por los ensambladores y carpinteros para los marcos, pero el pino en blanco -que sería dorado por Villegas- era la materia prima usual en retablos y esculturas, y se destinaría al adorno superpuesto al

${ }^{61}$ Los túmulos reales, mayores en tamaño, se solían hacer en poco más de un mes. Otro marco de Ratés de comienzos de 1662, el del retablo del Santo Cristo de la Obediencia en el convento madrileño del Caballero de Gracia, de similares características, se previó en el mismo plazo (G. ROSCALES OLEA, “Noticias sobre la pintura del Real Oratorio del Caballero de Gracia", Academia, 79, 1994, pp. 419-459). marco de peral ${ }^{62}$. Veremos que la descripción del inventario real de 1686 llama "retablo" a este ornato.

Los párrafos de las crónicas del 14 y 21 de noviembre de 1661 incluyen una aparente contradicción respecto al lugar donde se colocó el Pasmo en ambos actos. La primera dice que estaba "en el lugar del Retablo del Altar" y la segunda que "estaba pendiente, al lado del Altar". Al parecer, el día 14 se colocó la admirada pieza de Rafael donde antes estaba la gran tabla de la Adoración del Cordero místico de Michel Coxcie copia de los Van Eyck, y luciría con el adorno que se había hecho para esa ocasión. Pero el día 21 había sido repuesta en su lugar la pintura flamenca y el Pasmo fue colgado a un lado del altar, seguramente con el marco pero sin el adorno que lo rodeaba el día 14.

Puesto que queda claro por la carta de Torres de Medrano que era intención del rey desde el comienzo que el Pasmo presidiera la capilla real, hubiera resultado extraño un gasto elevado para un adorno efímero. Se ha tratado de explicar que no se hiciera entonces una instalación permanente por los acontecimientos que se sucedieron en la

\footnotetext{
${ }^{62}$ Ratés era un artífice idóneo para esta obra, pues había sido hasta ese momento escultor, entallador y contratista de pequeños retablos. Desde 1651 había hecho la talla y esculturas del retablo de la Virgen de la Fuencisla en su ermita segoviana para su responsable, Pedro de la Torre (A. MARCOS, "El retablo mayor del santuario de la Fuencisla", Estudios Segovianos, I, 249, pp. 251-254). En 1658 contrató seis esculturas para la capilla de San Isidro (F. MACHO ORTEGA, “La capilla de San Isidro en la parroquial de San Andrés de Madrid", Boletín de la Sociedad Española de Excursiones, XXVI, 1918, pp. 215-222). Fue propuesto al año siguiente por los arquitectos Ignacio Fox y Mateo Vallaroz como uno de los candidatos para hacer la talla del retablo de la parroquial de Valdemorillo que contrataron en 1659, y también su escultura (J. M. CRUZ YÁBAR, Op. cit, t. I, p. 93); se sabe que le encomendaron esta última (M. AGULLÓ Y COBO, Documentos sobre escultores, entalladores y ensambladores de los siglos XVI al XVIII, Valladolid, 1978, p. 132). En el noviciado jesuita de Madrid hizo, antes de 1661, el marco del altar mayor y dos retablos, y en este año ocho niños para éstos y diez leones para la capilla de la Inmaculada (Ibídem, pp. 111 y 132-133), tal vez por trazas del hermano Francisco Bautista.
} 
Corte durante el mes de noviembre: el día 1 murió el príncipe Felipe Próspero, el 6 nació el príncipe Carlos y el 10 murió el valido don Luis Méndez de Haro. Pero tanto luto y a la vez albricias no impidieron que el rey pudiera mostrar el cuadro con orgullo a sus cortesanos el día 14. El hecho de que una semana más tarde se hubiera retirado el adorno del Pasmo del lugar del altar no implica necesariamente que no volviera a ponerse. A la vista de la descripción del retablo de la Real Capilla en el inventario de 1686 como "un quadro en tabla... con marco negro y adornos de oro..." ${ }^{63}$, es razonable pensar que el adorno de Ratés y Villegas seguía allí. Si el Pasmo no presidió el altar de la capilla real hasta 1663, que es la fecha que señala el citado inventario, pudo deberse a ciertos cambios en la decoración de la capilla, como el óvalo que veremos que se pintó en torno al altar, una perspectiva atribuible a Juan Fernández de Gandía, y a algunas otras reformas de modernización del tabernáculo o del altar para adaptarlos al gusto del momento.

\section{EL ORNATO DE HERRERA BARNUE- $\mathrm{VO}$}

La hipótesis que formulamos a continuación identifica el ya citado dibujo de la Biblioteca Nacional atribuido a Sebastián de Herrera Barnuevo como primera idea para el adorno del Pasmo de 166164.

${ }^{63}$ Y. BOTTINEAU, Op. cit., pp. 439-440. Señala las proporciones modestas de la Capilla real, para la que calcula unas medidas de 19,50 m de largo por 7,80 m de ancho. En 1686 el inventario describe lo siguiente: "En la Capilla Real sirue de Retablo un quadro en tabla de quatro varas de alto y tres de ancho con marco negro y adornos de oro en que está pintado Christo Nro señor camino del Calvario, con nra señora, san Juan, y las Marías, y la turba, y ministros de los Judios original de mano de Rafael de Urbina, que por su primor y grandeza llaman el Pasmo, y la hizo traer el Rey nro señor D. Phelipe quarto del Reyno de Sicilia , y se colocó en la Capilla Real el año de 1663".

${ }^{64}$ El dibujo no tiene pitipié, lo que indica que sirvió como presentación al monarca.
El proyecto dibujado remata con un escudo de armas reales, por lo que tuvo que destinarse a algún recinto religioso patrocinado por los Austrias, pero no se conoce ninguna obra documentada que responda a las características allí figuradas. Presenta en el interior un recuadro central vacío, sobre el que se pegó un papel con una pintura de la Virgen con el Niño de diferente mano que el resto. Se deduce de ello que este cuadro no era el destinatario del retablo, y seguramente fue pegado sobre el papel original mucho más tarde. En cualquier caso, tampoco se conoce un altar de patrocinio regio que contuviera un asunto de pintura semejante.

El estilo del retablo es característico de la segunda mitad del siglo XVII ${ }^{65}$ pero los

${ }^{65} \mathrm{El}$ dibujo comienza con dos peldaños que llevan al altar. Éste y su mesa están cubiertos con una tela de terciopelo y flecos dorados, y la custodia por lo que parece un tejido de seda con los mismos flecos. Detrás está el ornato, que mediría, tomando como referencia el Pasmo en el recuadro y sin contar las gradas, unos 8,75 x 4,55 metros. Tienen los laterales sendas cartelas de las que cuelgan cordones con borlas, dos pedestalillos con decoración de serafín en una tarjeta, piedra, otra placa recortada con dos tarjetillas, y tarjeta que se expande por los lados. En la parte central hay un recuadro rectangular con marco de hojas y roleos en el interior. El cuerpo principal lo forma el cuadro de codillos u orejetas en la parte superior e inferior -donde hay una tarjeta-, doblados por cuatro molduras, la tercera exterior con hojillas y la cuarta con dos floroncillos arriba. En la parte central de esta moldura entra una guirnalda, sobre piedra y con festones a los lados, que parte de la cornisa y un estrecho friso con glifos y gotas. A los lados del marco hay caídas de dos cortinas descorridas por otros tantos angelillos, y otras dos parejas -delante de unos roleos- se sujetan a un cordón que cuelga de un anillo, en un adorno consistente en tarjeta, piedra, tarjetilla y gran placa recortada. Siguen dos pilastrillas; de la interior pende un festón de un gallón vegetal. El remate muestra dos palmas en los extremos, dos ángeles niños que sostienen el pesado cortinaje y se sientan sobre dos volutas. En la mitad hay una repisa en que apoya el escudo, con toisón de oro sostenido por dos angelillos, inscrito en una tarjeta y sin tener las armas dibujadas en su interior, rematado por corona real con tarjetilla y cruz. Flanquean el escudo dos águilas imperiales con dos ángeles encima tienen el comienzo de cada cortina; detrás hay dos palmas. Se fingen jaspeados -que se haría con pintura en la realidad- en pedestal, pilastras, adorno de encima, molduras interior y exterior del mar- 
detalles representados son muy particulares, como suele suceder en las invenciones del último maestro mayor de las obras reales elegido por Felipe IV. Tiene proporciones duplas bastante exactas que no son normales en los retablos: casi el doble de altura que anchura, y ésta, en su punto más ancho, es también dos veces la de la pintura. No aparecen calles laterales, apenas hay soportes o entablamento y el ático no tiene imágenes ni representaciones religiosas, sino que quedan bien patentes los atributos reales. $\mathrm{La}$ disposición y cantidad de adorno es excepcional.

Tres detalles llaman especialmente la atención. En primer lugar, tras el altar no aparece entorno arquitectónico ni se observan referencias al testero donde había de colocarse. En segundo lugar, el adorno crea la ilusión de que diez ángeles, a lo largo del marco, descorren dos cortinas laterales enrollándolas en cordones y tirando de ellos para descubrir el cuadro que había de colocarse en el centro. $Y$, por último, la custodia, exenta, aparece cubierta con un velo, lo mismo que el altar, igualmente velado, lo que podría explicarse por el hecho de que no formaban parte del proyecto, aunque se representaran sus bultos para observar el efecto.

Pensamos que el destino de esta originalísima invención fue servir de adorno al Pasmo en su presentación a los cortesanos. La pintura tiene las mismas proporciones que el marco interior del adorno -tres a dos y un poco- por lo que no hay inconveniente en este aspecto, como se puede comprobar por nuestra reconstrucción (Fig. 3). Pero este argumento, aunque indispensable, no es determinante, pues hay otras pinturas con esas proporciones. Trataremos de afianzar nuestra hipótesis abordando otros aspectos.

co, cornisa y repisa, y las cortinas serían también simuladas, pero de madera pintada.

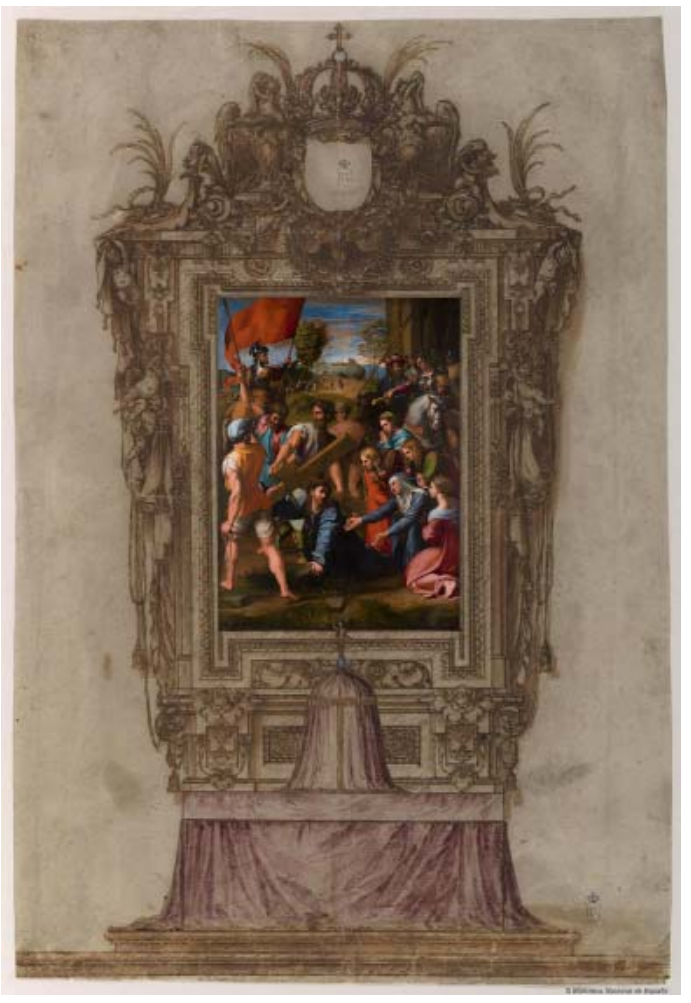

- Fig. 3. El Pasmo de Sicilia en su ornato. Reconstrucción del autor.

El hecho de que Villarreal ajustara las condiciones del adorno no constituye una prueba suficiente de que lo trazara, ya que no fue infrecuente en las empresas arquitectónicas de la época que el tracista fuera distinto de quien dictaba las condiciones. No se han documentado obras en que figure Villarreal como tracista de retablos o de adornos en madera, y su actividad se concentra en la construcción de edificios ${ }^{66}$. Así queda de manifiesto cuando, con ocasión de la entrada de la reina Mariana de Austria en 1649, elaboró las condiciones para los cuatro

${ }^{66}$ Tampoco su puesto de maestro mayor le reservaba esa tarea, pues, si bien sus antecesores en el puesto (Francisco de Mora, Juan Gómez de Mora y Alonso Carbonel) sí dieron trazas para retablos y otras estructuras decorativas en madera, se debió a que eran duchos también en esta materia, y la complejidad del adorno no era tan grande como en la segunda mitad de siglo, en que por lo general se dejaron las trazas de estas obras patrocinadas por la Corona en manos de especialistas, principalmente ensambladores. 
arcos que trazó Pedro de la Torre ${ }^{67}$. Siendo maestro mayor de la Villa y arquitecto de la capilla de San Isidro, encomendó a Sebastián de Herrera Barnuevo el diseño del tabernáculo para la urna del Santo ${ }^{68}$, aunque finalmente lo proyectara el ensamblador Juan de Lobera, como la restante decoración interior y exterior. Por tanto, pensamos que fue otro quien ideó la estructura de adorno para el Pasmo. Excluimos también a Ratés como posible tracista, pues no había participado en ninguna obra real antes de ésta y su trayectoria anterior no le acreditaba para una empresa tan delicada. Villegas era dorador y Juan Fernández de Gandía tuvo intervención posteriormente, en 1663, y no en la obra en madera, sino en la pintura de perspectiva.

La designación de Herrera Barnuevo para el máximo cargo en el escalafón de las obras reales es un asunto enigmático. Pese a que no tenía cargo alguno en la casa real ni había trabajado para empresas relacionadas con el Rey más que ocasionalmente, solo cinco días después del 10 de enero de 1662,

${ }^{67}$ T. ZAPATA FERNÁNDEZ DE LA HOZ, “La entrada de Mariana de Austria en la Corte. Fuentes literarias e iconográficas", en Fuentes y modelos de la pintura barroca madrileña, Madrid, 2008, pp. 105-204, especialmente p. 119.

${ }^{68}$ Villarreal y Herrera Barnuevo continuaban así la relación de sus maestros, Juan Gómez de Mora y Antonio de Herrera. Aunque se ha situado la fecha del dibujo de Herrera Barnuevo para el tabernáculo de San Isidro en su capilla de la parroquial de San Andrés de Madrid en torno a 1659 y 1660 por casi todos los autores, lo cierto es que un documento publicado por H. E. WETHEY, "Sebastián de Herrera Barnuevo", Anales del Instituto de Arte Americano e Investigaciones Estéticas, 11, 1958, pp. 11-65, especialmente p. 16, nos permite precisar la fecha del dibujo. Se libraron el 20 de diciembre de 16573.000 reales de ayuda de costa, 2.200 de ellos a Villarreal y 800 a Herrera Barnuevo, por su asistencia en la obra. La cantidad del primero es adecuada para planta y alzado del edificio, y la del segundo el precio habitual por una traza importante de retablo en Madrid. Pero hay que llevarlas a 1656, pues las primeras noticias de la construcción definitiva de la capilla, con las trazas por tanto elegidas, son de este año, y era normal en la época que los pagos se retrasaran. en que murió el maestro mayor José de Villarreal, Herrera Barnuevo era nombrado su sucesor $^{69}$.

Palomino explica lo ocurrido: "vacó a este tiempo la plaza de Maestro mayor de las obras reales; y discurriéndose en sugeto apto para este empleo, dixo a el Rey el Marques de Malpica, Mayordomo de semana entonces, que ninguno como Herrera sería apto para él, pero dudando el Rey lo quisiese admitir por la pretension tan diferente que tenia interpuesta, le dixo a el Marques lo dispusiese, el qual llamó a Herrera a el quarto del Rey: y habiendo llegado a hablar con el Marques, muy ageno de este intento, salió el Rey. Turbóse Herrera, y el Marques le dixo: no tiene que turbarse, sino bese la mano a su Magestad que le ha hecho merced de Maestro mayor, y Ayuda de la Furriera. El se quedó cortado, sin poderse ya resistir. Besó la mano al Rey, quien admiró la maña con que el Marques lo dispuso ${ }^{\prime 70}$.

La situación era paradójica. Herrera Barnuevo accedía a la plaza de maestro

${ }^{69}$ J. M. de AZCÁRATE RISTORI, “Datos para las biografías de los arquitectos de la Corte de Felipe IV", Revista de la Universidad de Madrid, XLII-XLIII, 1962, pp. 517-546, especialmente p. 533. Herrera comenzó a ejercer a partir del 1 de febrero de 1662.

${ }^{70}$ A. PALOMINO, Museo Pictórico y Escala Óptica, Madrid, 1715-1724 (ed. Aguilar, 1947), p. 969. Abundan en este asunto las afirmaciones de los pintores Andrés Smit y Juan Montero de Rozas en 1668 en su pleito para no sacar el paso de los Siete Dolores en su capilla del colegio madrileño de Santo Tomás: "Aviendo muerto Joseph de Villarreal, arquithecto y Maestro Mayor de las Obras Reales..., eligió Su Magestad de su propio motuo y sin consulta de la Junta de Obras y Bosques...a D. Sebastián de Herrera Barnuevo (que oy sirve este oficio) por Maestro Mayor, con noticia de que en él concurrían juntas nobleza conocida, y habilidades superiores en el exercicio y conocimiento de la pintura, escultura y arquitectura; sujeto es éste de quien hombres grandes y de la primera clase en los oficios primeros de la Casa Real afirman no aver tenido Palacio hombre semejante, por inteligencia y calidad en semejante ocupación" (E. LAFUENTE FERRARI, "Borrascas de la pintura y triunfo de su excelencia", Archivo Español de Arte, 62, 1944, pp. 77-103, especialmente p. 97). 
mayor de las obras reales contradiciendo la tradición de sus predecesores que habían sido antes aparejador primero o segundo, o bien ayuda de trazador. No podía aducir mérito alguno en obras para el Rey, solo los de su padre Antonio de Herrera, aparejador segundo o de la madera por más de un lustro y escultor real durante casi un cuarto de siglo. Y, lo que resultaba más asombroso, ni siquiera era aspirante al puesto, pues no había pedido el nombramiento, como se deduce de la anécdota de Palomino.

Cabe interrogarse sobre los motivos que llevaron al rey a la designación. Nada sabemos respecto a su relación con el superintendente de las obras reales, el marqués de Malpica, que debió de ser su decisivo valedor en este negocio ${ }^{71}$. Sin duda hubo una parte que se debió a la oportunidad de llegar en el momento: por entonces se preparaba la reforma de la capilla de Atocha $^{72}$, en que era idóneo un artífice con imaginación para inventar decoraciones, aunque careciera de profundos conocimientos en los aspectos constructivos. Pero tuvo que existir una ocasión que probara su capacidad para esta obra real y otras fu-

${ }^{71}$ En 1643 restituyó a Gómez de Mora en sus labores de maestro mayor del Alcázar y a Antonio de Herrera en su puesto de aparejador de la madera, del que había dimitido en 1630 por el ascenso de Alonso Carbonel (J. M. CRUZ VALDOVINOS, "Velázquez, el intruso" en In sapientia libertas. Escritos en homenaje al profesor Alfonso E. Pérez Sánchez, Madrid, 2007, pp. 429-434).

${ }^{72}$ Vid. J. M. CRUZ YÁBAR, “Juan Ortiz de la Rivilla y otros plateros en la capilla de Nuestra Señora de Atocha de Madrid", en Estudios de platería San Eloy, Murcia, 2010, pp. 235-250. A. E. PÉREZ SÁNCHEZ, Mostra di disegni spagnoli, Florencia, 1972, propuso que dos dibujos de Herrera Barnuevo en los Uffizi (inv. $\mathrm{n}^{\text {o }}$ 10165 y 10166) representaran espejos en lo alto y retratos en lo bajo para una galería de espejos en el palacio de Aranjuez, pero pensamos que fueron para la primera decoración interior del camarín de la Virgen contratada por Rizi y Carreño en 1663, pues se ve un vano para que entre la luz, cuadros con celajes típicos en estas estancias, y en lo bajo los huecos para reliquias citados en el segundo concierto de estos pintores de 1664 . turas, que tuvo que ser el proyecto para el adorno de la presentación del Pasmo. En septiembre de 1661, Villarreal debió recomendarle para esta tarea como ya había hecho en la capilla de San Isidro. Herrera Barnuevo presentaría este dibujo, que no pudo por menos de gustar al rey, quien tendría muy presente su nombre cuando surgió la ocasión de elegir maestro mayor en enero de 1662.

El adorno dibujado por Herrera Barnuevo ofrece una estructura muy novedosa en sus formas, como en la duplicación de tarjetas y piedras, las cortinas fingidas, las volutas que harían fortuna, la falta de arquitrabe y el friso atrofiado. Pero destaca tanto o más en el aspecto emblemático, con acertadas sugestiones del significado del acto a que se destinaba. El altar y el tabernáculo están velados porque así aparecerían en el acto, al tratarse de una ceremonia no religiosa. La iconografía tira más a la magnificación de la calidad del Pasmo que a establecer una relación con el pasaje evangélico que se representa. La figuración se centra en el descubrimiento del objeto que iba a asombrar a los cortesanos, con seis niños sentados que cargan con el peso del cortinaje en su arranque y otros cuatro que tiran con fuerza de los cordones para abrirlo a los costados. En el remate, las águilas emblema de los Austrias, y el escudo real con el toisón -aunque se excusara rellenarlo con las armas de Felipe IV-, que aluden a su triunfo al conseguir la pintura.

También gustaría al rey el doble efecto teatral de este ornato, pues los cortesanos verían al entrar en la capilla el habitual cortinaje que ocultaba el altar, y cuando los sumilleres de cortina la levantaran y vieran la pintura, observarían que los ángeles habían efectuado otro tanto en el adorno que la enmarcaba. Este efecto escenográfico, propio del arte efímero, tendría su eco en un retablo permanente, el de la Sagrada Forma del Escorial (1684-1690), donde se fingirían las 
cortinas no con madera, sino con el famoso lienzo de Claudio Coello ${ }^{73}$.

Llegados a este punto, hemos de plantearnos lo que pasó con el adorno trazado por Herrera Barnuevo. Como ya hemos anticipado en el punto anterior, la descripción de los autores del inventario de 1686 no deja lugar a dudas de que el marco de peral dado de negro y adorno de pino dorado que habían hecho Ratés y Villegas en 1661 era el retablo que cobijaba la pintura en aquella fecha. El capellán Mateo Fraso lo había descrito en una publicación del año anterior del siguiente modo: "Una moldura de dos palmos de ancho en medio de la qual por toda ella hay un festón de flores y frutos y en los ángulos y medios una tarjeta donde asientan seraphines de todo relieve, salen del festón dos movimientos, uno a la parte de adentro con alquitrave, corona, óbalos y filete; otro a la parte exterior co entalle de hojas y tarjetillas, al cabo recibe un pedestal q resalta con cartelones y en ella seraphines; todo este compuesto recibe en ménsulas triangulares sin basa y en lo alto hay una corona co dos frontispicios q covertidos en cornucopias reciven dos ángeles y una tarjetta adornada de festones y frutas para repisa de las armas reales $q$ se ven sustentados de las Aguilas del imperio y coprehendido todo en un obalo circular $q$ hace admirable la prospectiva" ${ }^{\prime 4}$.

Lo que vio Fraso tiene muchos elementos comunes con el ornato del dibujo,

\footnotetext{
${ }^{73}$ Herrera Barnuevo mismo ya había hecho algo parecido en el retablo de la Virgen de Guadalupe de las Descalzas (1653), donde una reja da acceso al nicho, y se repite la apertura, pero no real sino fingida, con unas puertas de madera que dejan ver el ornato, dispuesto con recuadros pintados al modo de los retablos del Rosario -con los quince misterios- o con reliquias, tres gradas debajo y remate de dosel para cobijar a la Virgen.

${ }^{74}$ M. FRASO, Op. cit, fol. 2 v.-3v. Cabe destacar que no hace la menor alusión al contraste cromático entre el marco interior negro y el adorno exterior dorado, que, en cambio, era el aspecto que más debía llamar la atención de quienes lo describieron en el inventario de 1686.
}

pero no es idéntico. Se mantienen el pedestal de cartelas y serafines, el recuadro central y en el remate las águilas imperiales y la corona real sostenida por dos ángeles entre festones de frutas y tarjeta. Hay algunas diferencias, pues no existe referencia a la invención de unos ángeles separando la cortina. El marco se enriquece con un festón central alrededor, en sus ángulos y mitades con ocho tarjetas con cabezas de serafines ${ }^{75}$, del cual salen unas ménsulas triangulares en vez de tarjetas bajo la cornisa, y en el remate los frontispicios no acaban en volutas sino que tienen forma de cornucopias ${ }^{76}$. El modelo diseñado, espectacular, presenta elementos que tendrían su dificultad para hacerlo pasar del dibujo al objeto y, en especial, la conservación, con elementos muy frágiles. Quizá las referencias al acto de la presentación eran demasiado explícitas y podrían parecer inconvenientes. En definitiva, hubiera sido factible como obra efímera, pero, para su duración, convenía sustituir algunos elementos, como debió hacerse.

El óvalo a que alude Fraso era, sin duda, pintado, y rodeaba el altar para rellenar el testero ${ }^{77}$. Pensamos que fue debi-

\footnotetext{
${ }^{75}$ Motivo popularizado ahora en los marcos de retablos en la corte.

${ }^{76}$ Un rasgo similar, aunque con tornapuntas en vez de cornucopias, encontramos en el retablo de los Santos Apóstoles del Paular (vid. nota 79) y en el del hospital de San José de Getafe, que por sus características atribuimos a Sebastián de Benavente, quien trabajó entre 1668 y 1672 en la localidad. Las pinturas del sagrario y remate parecen de Claudio Coello.
}

${ }^{77}$ Este relleno con pintura de lo que no cubría el retablo era habitual en el arte cortesano. Ha pervivido un ejemplo de 1680, el retablo antes de San Ildefonso en la catedral de Getafe, de Juan González (Archivo Histórico Diocesano de Getafe, Libro M. O. 4, fols. 256v., 361r. y 419r.), con un gran dosel pintado. Precisamente Herrera Barnuevo dispuso unas perspectivas similares en la capilla de Atocha. Francisco de Herrera el Mozo concertó el 4 de marzo de 1665, con memoria del 20 de febrero de Juan Bautista Martínez del Mazo, unas añadiduras que tenía que satisfacer para el 5 de abril, por 8.000 reales, 500 ducados de contado y los 2.500 al acabar en Pascua de Resurrección. Los andamios y el jaharrado se le daría hecho. La obra consis- 
do al pincel de Juan Fernández de Gandía, especialista en perspectivas, que hizo aquí su última obra ${ }^{78}$. El ornato del cuadro de que habla su hija muchos años después no tuvo que ser el marco y adorno, sino este óvalo, como dijo Aterido, que se pintaría entre 1662 y $1663^{79}$. Este conjunto de retablo

tía en pintar las seis pilastras y el medio punto sobre el balcón de la tribuna real en el lado del evangelio de la capilla mayor, los testeros de los dos lados de la puerta de jaspe de la sacristía, más teñir la yesería "para acortar con lo demás de la pintura echa". Todo tenía que ser fingido de estucos con los fondos de oro, según los dibujos elegidos por Felipe IV (Archivo Histórico de Protocolos de Madrid, prot. 10.988, fol. 479r.-481r.).

78 A. ATERIDO, Op. cit., interpretó que Gandía puso en riesgo su vida en esta obra, pero lo que se desprende de las afirmaciones de doña Teresa Ibarra es que su vida había estado en riesgo en muchos servicios al rey -seguramente arquitecturas efímeras y pinturas murales- pero no incluye esta, de la que dice tan solo que había sido el último servicio. En efecto, pidió a continuación su jubilación. Vid. más sobre este maestro en A. ATERIDO, "Mitelli, Colonna, Velázquez y la pintura mural en la corte de Felipe IV", en J. LL. COLOMER y A. SERRA DESFILIS (coords.), España y Bolonia: siete siglos de relaciones artísticas y culturales, Madrid, 2006, pp. 241- 264, especialmente 254-256.

${ }^{79}$ Gandía era un artífice multifacético, pero en labores de madera solía contratar con maestros especializados. Gandía y Ratés contrataron el 24 de enero de 1662, con traza del primero, el retablo citado del Cristo en el Caballero de Gracia. Tenía que hacer Ratés para esta pintura de cuatro por tres varas un tablero, dos cartelas que recibieran el marco de dos pies de ancho y una cornisa de un pie y cuarto de alto, todo adornado, de pino y dado de negro de manera que pareciera ébano. El tablero lo daría en seis días y lo demás en veinte, asentándolo en ocho más. Según labrara las piezas las daría a Gandía para su dorado, para el que disponía éste de 24 días. El escultor cobraría 1800 reales y el pintor 500. Se decidió aumentar un pie de ancho y alto el lienzo y se pagó la modificación del marco a Ratés, más tarjetas y cartelas en vez de argollones y aros como demasías en 595 reales más. El dorado de éstas, de la cornisa, que se talló finalmente, y del bisel, dio a Gandía 300 reales más, aunque cayó enfermo y lo acabaron sus oficiales. Percibió otros 777 reales por la restauración y añadidos del lienzo, traza del marco y de unas arañas; el pintor Juan Pérez tasó todo en 6712 reales (documentado por G. ROSCALES OLEA, Op. cit., pp. 426-428). Las coincidencias con el ornato recién acabado del Pasmo son evidentes en cuanto a artífices, y perspectivas para el Pasmo perduró hasta 1700 , en que fue sustituido por un retablo de pórfido venido de Italia ${ }^{80}$. tiempos y precios, y también en estilo, aunque no tuviera el rico remate de éste y prueba la influencia del modelo. Ratés debió hacer por estas fechas un retablo que mezclaba rasgos del ornato del Pasmo, el dedicado antiguamente a los Apóstoles Pedro y Pablo conservado en la cartuja del Paular, donde trabajó mucho tiempo, al menos desde 1662. Otra obra derivada de este estilo de Herrera Barnuevo que debió hacer Ratés en la Cartuja fue el espectacular cancel que separaba los coros de la iglesia, del que queda fotografía en el Archivo Moreno.

${ }^{80}$ M. J. MUÑOZ GONZÁLEZ, Op. cit., pp. 50-69. En el inventario de 1701 (G. FERNÁNDEZ BAYTÓN, Inventarios reales. Testamentaría del rey Carlos II. 17011703, Madrid, 1975, t. I, p. 70) se mencionó el Pasmo entre las pinturas desmontadas de las bóvedas del Tiziano. Aunque en general se ha pensado que la tabla siguió en el Alcázar y se salvó del incendio de 1734, en 1715 pasó a la cámara de la reina en el palacio del Buen Retiro, donde le hizo un nuevo marco el ensamblador Francisco Álvarez (J. J. JUNQUERA Y MATO, “Algunos datos sobre el Pasmo de Rafael y otras pinturas enviadas al Buen Retiro en 1715", Arte Español, XXV, 1963-1967, pp. 108-111. Citado por J. M. RUIZ MANERO, Op.cit., p. 62). Más adelante (1772) ya sí figuró en el Palacio Nuevo. 